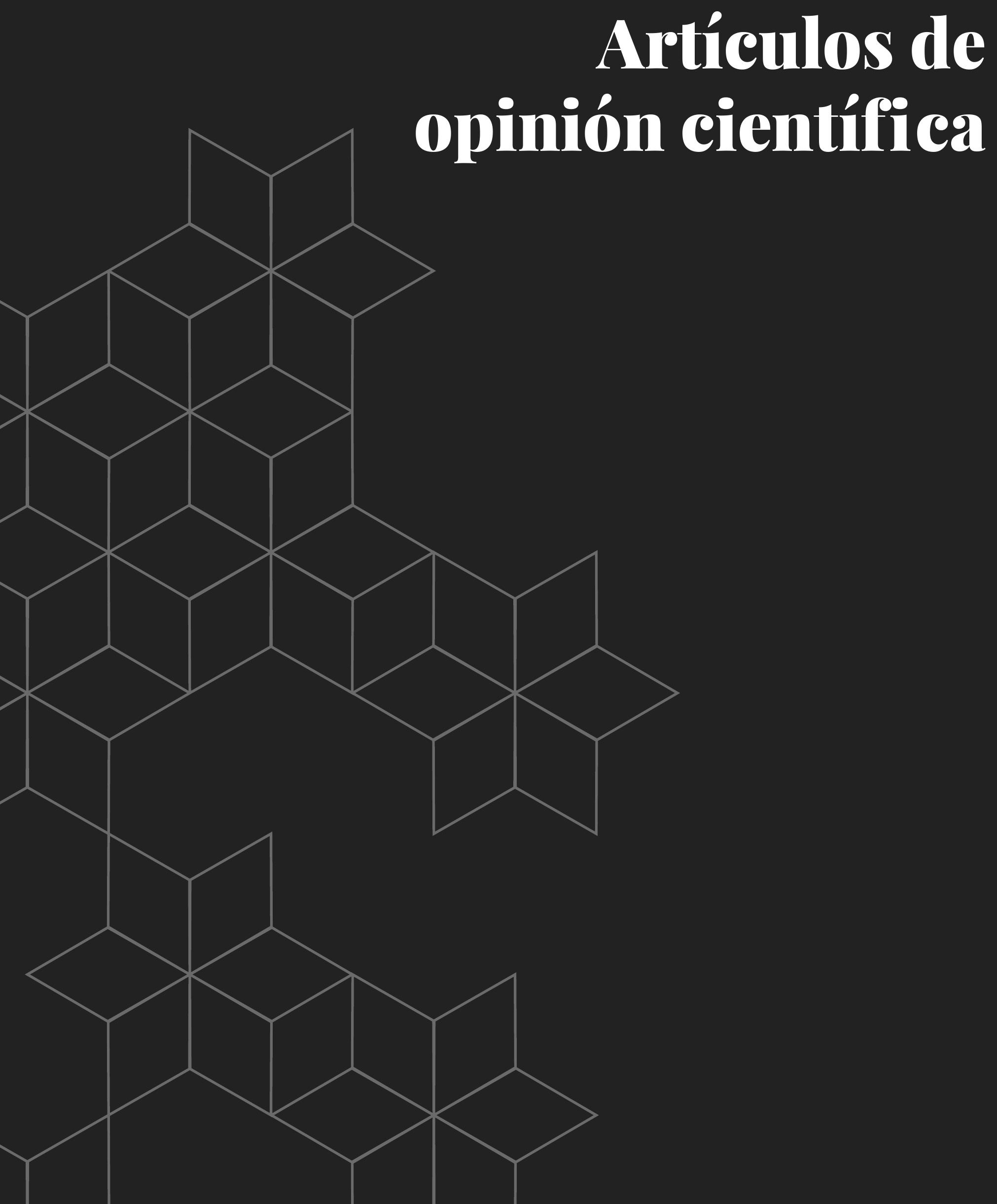




\title{
Salud pública en Guatemala: Necesidad de un desarrollo integral
}

\author{
Dr. Miguel A. Garcés de Marcilla
}

Los datos epidemiológicos nacionales muestran con toda claridad la polarización social y económica que existe en Guatemala, y se considera que es esta misma polarización la que causa que en el país se hallen, simultáneamente, dos perfiles distintos de daño a la salud: uno antiguo, que ha afectado históricamente a la mayor parte de la población y otro incipiente o moderno, de menor relevancia en el presente, pero que será muy importante en el futuro, al ocurrir mejorías en las condiciones económicas y sociales de los guatemaltecos y guatemaltecas, y cambiar el perfil de daño.

Estos perfiles se distribuyen en forma diferencial según clase social, etnia, área de residencia, grupo etario y género, entre otras variables.

El «perfil antiguo» se caracteriza por alta incidencia y mortalidad por enfermedades infecciosas, carencias nutricionales y deficiencias en la salud reproductiva. Este es causante de la mayor morbilidad y mortalidad en el país; afecta principalmente a la población pobre, sobre todo infantil y a la mujer rural e indígena. Las poblaciones con este perfil tienen altas tasas de fecundidad y mortalidad, así como estructura etaria predominantemente joven.

El «perfil incipiente o moderno» se caracteriza por la alta incidencia y prevalencia de enfermedades cardiovasculares, cáncer, diabetes y otras enfermedades crónicas, así como por el incremento de la violencia y alteraciones varias de la salud mental. Este afecta principalmente a poblaciones urbanas, no indígenas, adultas, de ambos sexos, de estratos socioeconómicos medio y alto. Es producido por los cambios en los modos de vida que ocurren con mayor intensidad en este grupo (consumo de productos dañinos a la salud como tabaco y alimentos altos en grasas saturadas, unido a baja ingesta de frutas y verduras, sedentarismo, conflicto social, conductas propensas a los accidentes automovilísticos) y por otros relacionados al proceso de urbanización en general (deterioro de la salud mental, conductas violentas y accidentes en general), también por el envejecimiento de esta población debido a una menor natalidad y mayor esperanza de vida.

La presencia simultánea de los dos perfiles en un país se ha denominado por varios autores del área de la epidemiología social como "polarización epidemiológica», que es la situación que ocurre en Guatemala.

Cuando en un país se presenta esta polarización, se hace indispensable el análisis estratificado por variables: étnicas, lingüísticas, sociales, económicas y biológicas seleccionadas, para 
conocer la situación concreta de cada grupo de población y planificar acorde a las necesidades correspondientes.

El desarrollo de la Salud Pública en Guatemala es, por tanto, complejo, porque debe responder en su planificación y ejecución, a las realidades concretas de sus diversos espacios sociogeográficos y poblacionales; realidades que deben estudiarse en forma integral, poniendo atención no solo a las características de morbilidad y mortalidad, sino, más importante aún, a sus condiciones de vida: niveles de ingresos, disponibilidad y tipo de trabajo, alimentación, vivienda, educación, oportunidades de recreo, vida en familia, desarrollo de la creatividad y gozo del arte, entre otras variables.

Este análisis integral se desarrolla en lo que modernamente se ha llamado el campo de la Epidemiología Social y es necesario para la planificación y ejecución integral, sobre todo equitativa, de los servicios de salud.

La historia ha demostrado, sin lugar a dudas, la causalidad de la salud a través de procesos que se inician en las condiciones de vida de las poblaciones; por ello, se requiere que los trabajadores de la Salud Pública aborden tales condiciones para que el desarrollo de la salud sea efectivo, equitativo y de calidad.

Una responsabilidad esencial en la Salud Pública es el «liderazgo en salud», que se refiere a la convocatoria y dirección intersectorial de acciones estatales, multidisciplinarias, que contribuyan a mejorar las condiciones de vida y, por tanto, 12 de salud.
Hay dos hechos que se consideran importantes de resaltar: (1) que las mejores condiciones de salud poblacional solo se han conseguido históricamente en sociedades con altos niveles de equidad, donde se hace efectivo el concepto de «ciudadanía en salud» y (2) que para que un país progrese es requisito indispensable el desarrollo integral y equitativo de sus ciudadanos, donde la salud es requisito indispensable, junto a la educación, el trabajo digno y la seguridad, para alcanzar altos niveles de desarrollo humano.

Por todo lo anterior, se considera muy alta la responsabilidad que tiene todo trabajador y trabajadora de la salud, quienes deben promover la equidad en salud, en un marco de desarrollo social y económico, justo y solidario.

La tarea ahora es caminar por la vía correcta para alcanzar lo que todos deseamos para Guatemala: prosperidad social y económica, paz, seguridad y democracia auténtica, lo que solo se logra con salud integral: física, biológica, mental $y$, sobre todo, social. 